Vulnerabilidades urbanas en los países andinos (Bolivia, Ecuador, Perú)

\title{
El sismo del 15 de agosto de 2007 en la Margen Izquierda del Río Rímac (Lima)
}

Le séisme du 15 août 2007 dans la Margen Izquierda del Río Rímac (Lima)

The August 15, 2007 earthquake in the Margen Izquierda del Río Rímac

(Lima)

Jérémy Robert y Robert D’Ercole

\section{(2) OpenEdition}

1 Journals

Edición electrónica

URL: http://journals.openedition.org/bifea/2310

DOI: $10.4000 /$ bifea.2310

ISSN: 2076-5827

Editor

Institut Français d'Études Andines

Edición impresa

Fecha de publicación: 1 diciembre 2009

Paginación: 515-526

ISSN: 0303-7495

Referencia electrónica

Jérémy Robert y Robert D'Ercole, «El sismo del 15 de agosto de 2007 en la Margen Izquierda del Río Rímac (Lima) », Bulletin de l'Institut français d'études andines [En línea], 38 (3) | 2009, Publicado el 01 junio 2010, consultado el 17 noviembre 2020. URL : http://journals.openedition.org/bifea/2310 ; DOI : https://doi.org/10.4000/bifea.2310

\section{(c) (†) $\ominus$}

Les contenus du Bulletin de l'Institut français d'études andines sont mis à disposition selon les termes de la licence Creative Commons Attribution - Pas d'Utilisation Commerciale - Pas de Modification 4.0 International. 


\title{
El sismo del 15 de agosto de 2007 en la Margen Izquierda del Río Rímac (Lima)
}

\author{
Jérémy Robert* \\ Robert $D^{\prime}$ Ercole $^{* *}$
}

\section{Resumen}

El 15 de agosto de 2007, el sismo de Pisco provocó enormes daños en el departamento de Ica, al sur de Lima. También se observaron daños en la capital del Perú, esencialmente en los barrios más pobres. Sin embargo, estos aparecen ampliamente subestimados por los poderes públicos, tal como lo demuestra el análisis de los efectos del sismo en la Margen Izquierda del Río Rímac (MIRR), conjunto de barrios populares de Lima caracterizados por su pobreza y un hábitat precario. El estudio de caso pone en evidencia los vacíos de la gestión pública de la crisis en estos barrios, traduciendo una vulnerabilidad de fondo ligada a la marginalización y a la exclusión social de la MIRR.

Palabras clave: gestión de crisis, vulnerabilidad, marginalidad, exclusión, MIRR, sismo de Pisco

\section{Le séisme du 15 août 2007 dans la Margen Izquierda del Río Rímac (Lima)}

\section{Résumé}

Le 15 août 2007 le séisme dit de Pisco, a fortement affecté le département d'Ica au Sud de Lima. Les dommages ont aussi été observés dans la capitale, essentiellement dans les quartiers les plus pauvres. Ils apparaissent cependant largement sous-estimés par les pouvoirs publics, comme le montre l'analyse des effets du séisme dans la Margen Izquierda del Río Rímac (MIRR), ensemble de quartiers populaires de Lima caractérisés par leur pauvreté et un habitat précaire. L'étude de cas met en évidence les

* Institut Français d'Études Andines (IFEA, UMIFRE 17, CNRS-MAEE), programa Pacivur, Avenida Arequipa 4500, Miraflores, Casilla 18-1217, Lima 18, Perú. E-mail: jeremy.robert@univ-savoie.fr

** Institut de Recherche pour le Développement (IRD), UR 029, programa Pacivur, Calle Teruel 357, Miraflores, Casilla 18-1209, Lima 18,Perú. E-mail: robert.d'ercole@ird.fr 
lacunes de la gestion publique de la crise dans ces quartiers traduisant une vulnérabilité de fond liée à la marginalisation et à l'exclusion sociale de la MIRR.

Mots clés : gestion de crise, vulnérabilité, marginalité, exclusion, MIRR, séisme de Pisco

\title{
The August 15, 2007 earthquake in the Margen Izquierda del Río Rímac (Lima)
}

\begin{abstract}
On August 15, 2007, the Pisco earthquake strongly damaged the department of Ica in the South of Lima. Damages have been also observed in the capital, essentially in the poorest neighbourhoods. Public authorities have underestimated these damages, as seen by the analysis of the earthquake effects in the Margen Izquierda del Río Rímac (MIRR) - Lima popular neighbourhoods characterized by their poverty and a precarious habitat. The case study discussed in this article reveals the weakness of the public crisis management in these neighbourhoods. This weakness conveys the underlying vulnerability resulting from the marginalization and the social exclusion of the MIRR.
\end{abstract}

Key words: crisis management, vulnerability, marginality, MIRR, Pisco Earthquake

\section{DESCRIPCIÓN DEL EVENTO}

Los terremotos causados por la subducción de la placa tectónica de Nazca bajo la placa sudamericana representan uno de los riesgos mayores en el Perú. La costa del Pacífico ha sido afectada duramente por violentos sismos, y en particular la capital peruana en 1746 (más de 3000 muertos), en 1940 (180 muertos y 3500 heridos), en 1966 y en 1974. El último afectó severamente las provincias de Pisco, Chincha e Ica el 15 de agosto de 2007. Este alcanzó una magnitud 8 en la escala de Ritcher y causó 596 víctimas y 1291 heridos, provocando además daños considerables a las infraestructuras: 47225 viviendas destruidas, 44927 inhabitables y 44810 afectadas1. Aunque el epicentro estuvo relativamente alejado de Lima, a aproximadamente $200 \mathrm{~km}$, este sismo estremeció con fuerza la capital peruana. Los daños provocados, más de doscientas viviendas destruidas según fuentes oficiales y varias centenas de viviendas afectadas, se concentraron esencialmente en los barrios más pobres.

En el distrito del Cercado de Lima, los barrios de la Margen Izquierda del Río Rímac (MIRR) fueron particularmente afectados. Caracterizada por su pobreza y un hábitat precario, la MIRR aglomera a más de 80000 habitantes y forma parte de los barrios populares más antiguos de Lima. Aunque situada a menos de $2 \mathrm{~km}$ del centro histórico y de los centros de decisión política de Lima y del Perú, la MIRR aparece como un espacio marginal, tanto física como socialmente (D'Ercole \& Sierra, 2008). La ruptura espacial está materializada por la avenida Alfonso Ugarte, frontera entre el centro valorizado y los barrios populares que simbolizan la informalidad, la pobreza e incluso la delincuencia.

1 Evaluación Indeci (Instituto Nacional de Defensa Civil) del 29 de octubre de 2007. 
Más allá de la constatación de los daños que las fuentes oficiales han ampliamente subestimado, el análisis de los impactos del sismo en la MIRR permite el reconocimiento de diferentes formas de vulnerabilidad. Se trata en particular de la marginalización y de la exclusión características de la MIRR tanto en periodo normal como en periodo de crisis, a semejanza de aquella generada por el sismo del 15 de agosto de 2007.

\section{CONSECUENCIAS}

La evaluación oficial de los daños realizada sobre el conjunto de las zonas afectadas muestra a priori un escaso impacto del sismo en Lima. En toda el área urbana Lima/Callao, el Instituto Nacional de Defensa Civil (Indeci) registra 841 personas damnificadas, 202 viviendas destruidas y 114 afectadas2. Sin embargo, las informaciones presentadas bajo la forma de un balance a escala de los distritos son bastante someras. En todo el Distrito del Cercado de Lima se registran tan solo 7 viviendas destruidas y 2 afectadas. Empero, según el informe de las inspecciones de Defensa Civil del Cercado de Lima3, a escala de este distrito y de la MIRR, los daños observados han sido mucho más importantes.

Cuadro 1 - Evaluación del riesgo de colapso de las construcciones en el Cercado de Lima después del sismo de 2007

a. Edificios públicos o que reciben público

\begin{tabular}{|l|c|c|c|c|c|c|}
\hline $\begin{array}{c}\text { Grado de } \\
\text { riesgo de } \\
\begin{array}{c}\text { colapso (de } \\
\text { toda o parte de } \\
\text { la estructura) }\end{array}\end{array}$ & $\begin{array}{c}\text { Estableci- } \\
\text { mientos } \\
\text { escolares }\end{array}$ & $\begin{array}{c}\text { Estableci- } \\
\text { mientos } \\
\text { comerciales }\end{array}$ & $\begin{array}{c}\text { Instituciones } \\
\text { públicas y } \\
\text { corporativas }\end{array}$ & Iglesias & Total & $\begin{array}{c}\% \text { del total } \\
\text { inspeccionado }\end{array}$ \\
\hline Riesgo elevado & 26 & 7 & 10 & 6 & 49 & 21,6 \\
\hline Riesgo medio & 71 & 22 & 43 & 12 & 148 & 65,2 \\
\hline Riesgo bajo & 11 & 2 & 16 & 1 & 30 & 13,2 \\
\hline $\begin{array}{l}\text { Total } \\
\text { inspeccionado }\end{array}$ & 108 & 31 & 69 & 19 & 227 & 100 \\
\hline
\end{tabular}

b. Viviendas particulares

\begin{tabular}{|l|c|c|}
\hline $\begin{array}{c}\text { Grado de riesgo de colapso (de } \\
\text { toda o parte de la estructura) }\end{array}$ & Viviendas & \% del total inspeccionado \\
\hline Riesgo elevado & 89 & 42,6 \\
\hline Riesgo medio & 87 & 41,6 \\
\hline Riesgo bajo & 33 & 15,8 \\
\hline Total inspeccionado & 209 & 100 \\
\hline
\end{tabular}

Fuentes: Inspecciones realizadas por la Defensa Civil del Cercado de Lima (2007)

2 Cf. nota 1.

3 En este caso se trata de Defensa Civil Municipal mientras Indeci constituye la Defensa Civil Nacional. 
Como bien lo ilustra el cuadro 1a, más del $20 \%$ de los edificios públicos (o que reciben público) inspeccionados fueron considerados como de alto riesgo de colapso parcial o total (es decir 49 locales). En la mayoría de los casos se recomendó la inspección profunda de las estructuras, así como la realización de obras supervisadas por profesionales cuando se constataban daños más severos.

A escala de la MIRR, los principales locales escolares presentaban fisuras como los $\mathrm{CE}^{4}$ El Planeta, Virgen de La Merced, Carrión y el colegio Guzmán, entre otros. Defensa Civil recomendó la clausura de varias aulas en el CE Canadá (barrio $1^{\circ}$ de Mayo), así como la reconstrucción de las estructuras del CE 1161 del barrio El Planeta. Los locales religiosos también sufrieron. Defensa Civil restringió el acceso a la Capilla Inmaculada Concepción, también en el barrio $1^{\circ}$ de Mayo, pues una de las paredes laterales presentaba una amplia fisura que traducía el debilitamiento del edificio.

Los daños también fueron importantes en lo que atañe a las viviendas. Sobre 209 casas inspeccionadas a escala del Cercado de Lima, 89 fueron consideradas de alto riesgo de colapso y 87 de riesgo medio (cuadro 1b). Sin embargo es necesario destacar que las inspecciones de las viviendas no fueron sistemáticas, contrariamente a aquellas de los edificios públicos. En efecto, la mayoría de las inspecciones fueron realizadas a solicitud de los propietarios. Es importante considerar este procedimiento porque explica en parte la escasa constatación de daños en las viviendas (solamente 0,3\% de las viviendas fueron inspeccionadas en el Cercado de Lima), en particular en la MIRR. Efectivamente, Defensa Civil, encargada de las inspecciones, es también responsable de la evaluación de las zonas de riesgo y emite su opinión en cuanto a su habitabilidad. Por esta razón, los habitantes instalados en zona de riesgo5, dada su condición de ilegalidad, no acudieron a Defensa Civil por temor a ser desalojados.

Paralelamente a las inspecciones de Defensa Civil, la ONG italiana Coopi (Cooperazione Internazionale), dentro del marco de un proyecto Dipecho (Disaster Prepardness ECHO) de preparación ante desastres financiado por la Comisión Europea, realizó una evaluación de los daños en la MIRR en enero de 2008. Esta permitió mostrar que los daños fueron más importantes que aquellos presentados por las fuentes oficiales. La comparación entre el número de evaluaciones de daños y aquellos realmente observados muestra la subestimación general de los daños en Lima y lo poco que se tomó en cuenta a los sectores marginales (cuadro 2).

4 CE: Centro Educativo.

5 Riesgo asociado a la inestabilidad del suelo 
Cuadro 2 - Diferencias en materia de evaluaciones de viviendas y de daños observados entre la aglomeración Lima/Callao, el Cercado de Lima y la MIRR

\begin{tabular}{|c|c|c|c|}
\hline & Lima/Callao & Cercado de Lima & MIRR \\
\hline $\begin{array}{l}\text { Número de viviendas } \\
\text { (y población corres- } \\
\text { pondiente) según el } \\
\text { censo del INEI (2007) }\end{array}$ & $\begin{array}{l}1913853 \\
\text { (8 } 482619 \text { habs.) }\end{array}$ & $\begin{array}{l}75418 \\
\text { (299 } 493 \text { habs.) }\end{array}$ & $\begin{array}{l}18221 \\
(80741 \text { habs.) }\end{array}$ \\
\hline $\begin{array}{l}\text { Viviendas sometidas a } \\
\text { una evaluación }\end{array}$ & ? & $\begin{array}{l}209(0,3 \%) \text { inspec- } \\
\text { cionadas por Defensa } \\
\text { Civil del distrito }\end{array}$ & $\begin{array}{l}795 \quad(4,4 \quad \%) \\
\text { inspeccionadas por } \\
\text { la ONG Coopi }\end{array}$ \\
\hline Daños observados & $\begin{array}{l}7 \text { viviendas } \\
\text { destruidas, } 2 \\
\text { afectadas (Indeci) }\end{array}$ & $\begin{array}{l}89 \text { viviendas de riesgo } \\
\text { elevado de colapso y } \\
87 \text { de riesgo medio }\end{array}$ & \begin{tabular}{lrr}
258 & \multicolumn{2}{r}{ viviendas } \\
dañadas de las \\
cuales 22 con \\
más de $50 \% \%$ \\
de su estructura \\
colapsada.
\end{tabular} \\
\hline
\end{tabular}

Sobre un total de 795 casas y edificios públicos evaluados por la ONG Coopi, un tercio (o sea 258) muestra huellas de daños; de ellos 22 viviendas presentan más del 50 \% de su estructura derrumbada (figs. 1-4). Los edificios dañados están representados en la figura 5 .

La distribución de los daños evidencia con claridad 2 zonas particularmente afectadas. Estas corresponden a los barrios $1^{\circ}$ de Mayo y Villa María del Perpetuo Socorro. Estos barrios situados sobre antiguas zonas de relleno sanitario, aparecen menos consolidados en relación con los barrios vecinos. Las calles no están asfaltadas y las casas son precarias, igual que el acceso a los servicios públicos, tal como es el caso de la red de agua potable y de desagüe. Se observan también

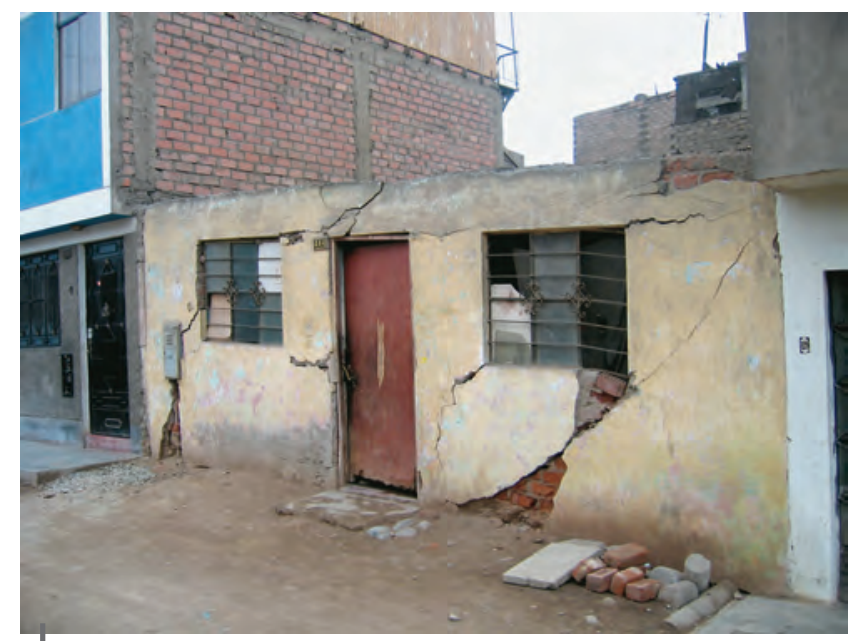

Figura 1 - Casa muy dañada en el barrio $1^{\circ}$ de Mayo

Foto: R. D'Ercole, 16.09.2007 


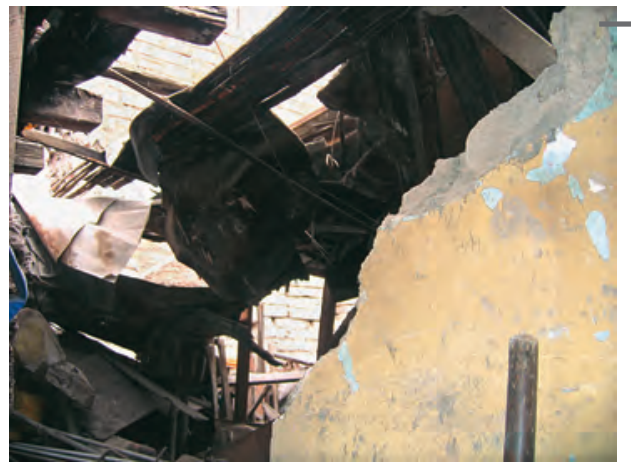

Figuras 2 y 3 - Habitante del barrio $1^{\circ}$ de Mayo mostrando los daños en su vivienda y en particular el techo destruido. Un mes después del sismo, esta persona continuaba ocupando su vivienda durante el día. En la noche, unos vecinos la albergaban

Fotos: R. D'Ercole, 16.09.2007
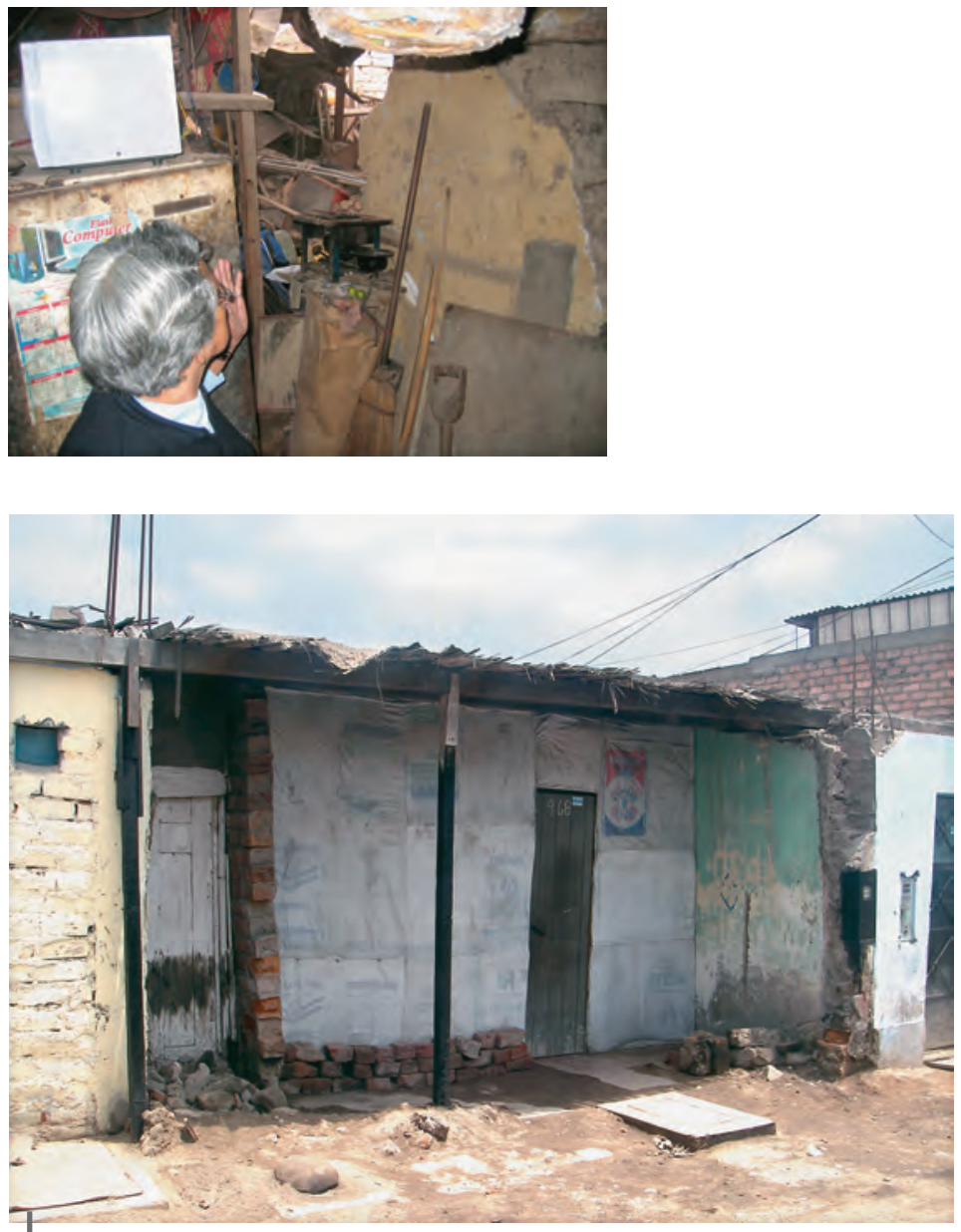

Figura 4 - Casa dañada en el barrio de Villa María del Perpetuo Socorro: la pared de la fachada, actualmente hecha de bolsas de yute, se desplomó tras el sismo de 2007

Foto: J. Robert, 27.11.2007 


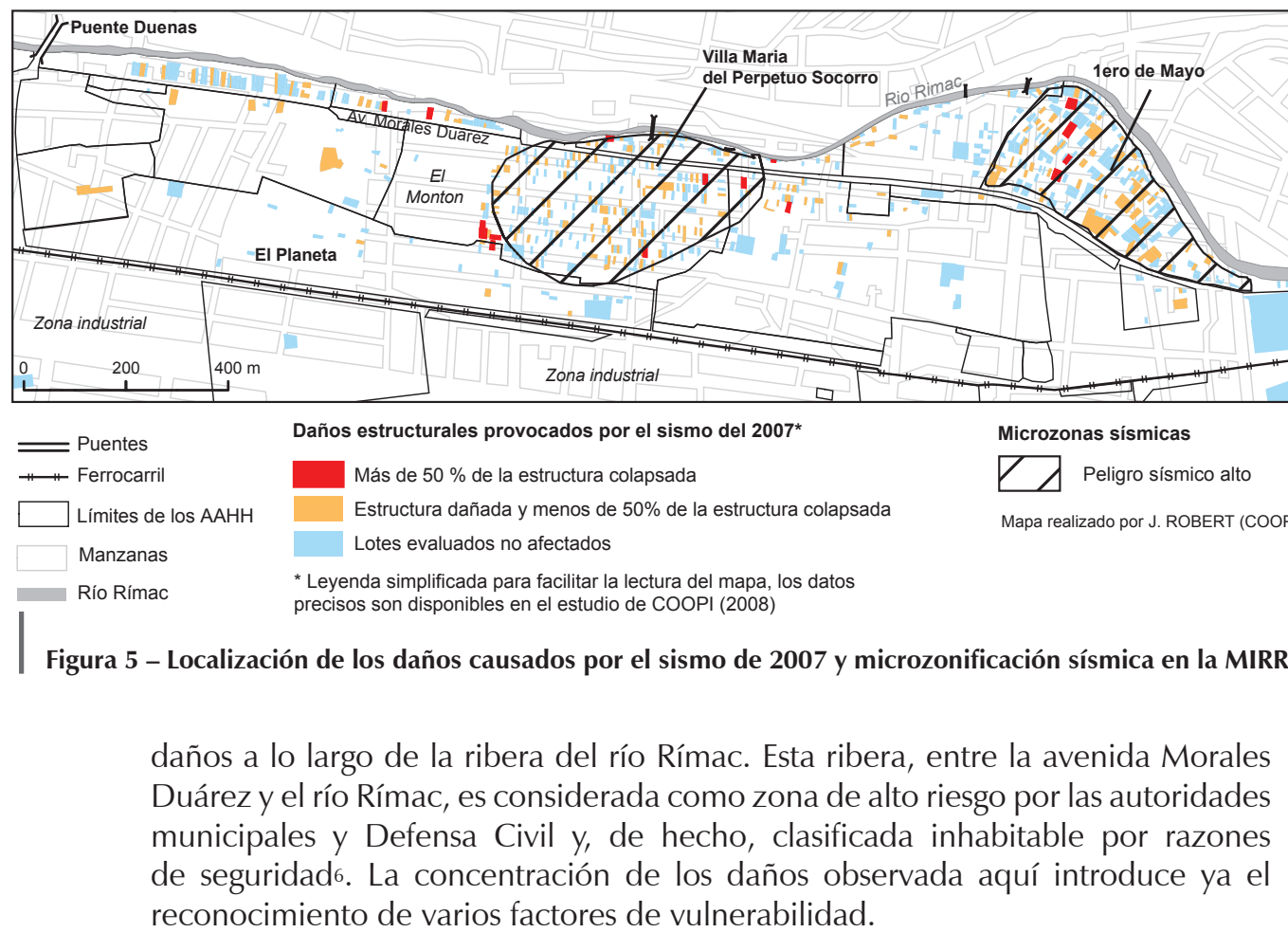

\section{FACTORES DE VULNERABILIDAD}

La mala calidad de los suelos y de las construcciones constituyen los principales factores de vulnerabilidad que explican la amplitud de los daños observados en la MIRR.

La microzonificación sísmica (Bernal \& Tavera, 2008) realizada por el Instituto Geofísico del Perú (IGP) dentro del marco del proyecto Dipecho, ha permitido identificar dos zonas susceptibles de amplificar las aceleraciones sísmicas (fig. 5). Estas coinciden mucho con las zonas más fuertemente dañadas por el sismo. Se destaca la existencia de formaciones superficiales inestables, ligadas a la presencia de rellenos más o menos compactados y se explica por los procesos históricos de ocupación del sector.

La ocupación de la MIRR se ha realizado de manera informal y progresiva a partir de los años 1940. La población se asienta sobre terrenos inicialmente dedicados a la explotación agrícola, entre la vía férrea que une el centro histórico de Lima y el puerto de El Callao, y el río Rímac. Detrás de las murallas del centro histórico7,

6 Ver artículo de Robert \& Sierra en este volumen, págs. 595-621.

7 Las murallas fueron en gran parte destruidas entre 1872 y 1880. 
estos espacios son utilizados también para la descarga de basura, la explotación de materiales de construcción, y posteriormente, para la instalacion de una zona industrial. Estos constituyen una importante fuente de actividad para la población de migrantes excluida del centro histórico.

Los barrios populares se han densificado en este sector $y$, frente a la falta de espacio, numerosos terrenos han sido rellenados, permitiendo la valorización de zonas pantanosas o del lecho mayor del río. Esta ganancia de espacio sobre el río es realizada con materiales diversos, en particular con materiales de relleno sanitario provenientes del centro histórico, así como con materiales y escombros de construcción. Hoy en día densamente pobladas, las zonas de relleno, a menudo mal consolidadas, contribuyen a la inestabilidad de las construcciones. En los sectores más críticos, las casas colapsan y parecen «saludar» según la expresión local. Estas modalidades de ocupación han contribuido también a la incisión del lecho menor del río, provocando la inestabilidad actual de las riberas del río Rímac.

A la mala calidad de las construcciones se añade la inestabilidad del suelo, lo que da cuenta de los escasos recursos económicos de las poblaciones. La mayoría de las casas han sido construidas sin asistencia técnica. Un poco más del $5 \%$ (937) están hechas de adobe, material que puede resultar muy peligroso en caso de no respetar las técnicas de construcción antisísmicas, y más del $3 \%$ son de materiales precarios, como madera (aproximadamente 600 viviendas) quincha o estera8 (cerca de un centenar). Además, es frecuente que en un primer momento solo se construya el primer piso, mientras que los pisos siguiente se habilitan según las posibilidades económicas de las familias. En este caso, la continuidad de los elementos portadores rara vez es respetada, lo que contribuye a la fragilidad del conjunto de la estructura.

Las vulnerabilidades que se expresan por la mala calidad del suelo y de las construcciones están fuertemente ligadas a las condiciones de precariedad y de pobreza que caracterizan a la MIRR. Estas provienen de una vulnerabilidad socioeconómica que explica la escasa capacidad de la población para resistir y salir indemne de un evento finalmente menor, dado el alejamiento del epicentro del sismo. Esta vulnerabilidad de fondo se evidencia también en la marginalización y la exclusión social de la MIRR. En cambio, sus terrenos presentan interés para los poderes públicos que desean valorizar las riberas del río Rímac, acondicionando ahí espacios verdes. La gestión política de este espacio está entonces caracterizada por un diálogo difícil, incluso conflictivo entre autoridades y comunidades. Esto se traduce en particular en un inmovilismo en materia de mejoramiento del hábitat y en la ausencia de medidas de prevención de los riesgos por parte de los poderes públicos, lo que tiende a favorecer la intensificación de la vulnerabilidad (D’Ercole \& Sierra, 2008; Robert \& Sierra, en este volumen, pp. 595-621).

8 Las construcciones de quincha utilizan un material tradicional que consiste en un trenzado, generalmente de caña, que después es recubierto de barro. En cambio, las construcciones de estera no utilizan ese recubierto. 


\section{GESTIÓN DE CRISIS}

La gestión oficial de la crisis se concentró casi exclusivamente en el departamento de Ica al sur de Lima, en donde los daños fueron los más severos. En esta zona, la ayuda de emergencia se distribuyó de manera desigual, privilegiando a las ciudades (en particular la de Pisco) y la costa en detrimento del mundo rural y la sierra (D'Ercole et al., 2008). Los barrios pobres de Lima figuran igualmente entre los dejados atrás. En efecto, fuera de algunas excepciones como el distrito acomodado de La Molina, los barrios pobres, entre los cuales está la MIRR, son los que sufrieron los daños más notables en la capital. Sin embargo la atención de los poderes públicos, de la ayuda humanitaria o de la prensa fue en este caso practicamente inexistente.

En los sectores centrales de Lima, solamente algunas intervenciones fueron realizadas por los bomberos de la Central Roma (Cercado de Lima), tras el colapso de construcciones en Barrios Altos y en el distrito del Rímac, pero no en la MIRR. Algunos artículos periodísticos mencionan daños en la capital, como por ejemplo en El Comercio del 20 de agosto de 2007: «Viviendas en al menos 9 zonas de Lima están inhabitables o dañadas». El artículo permite observar la ausencia de una evaluación oficial de los efectos del sismo, reportando los siguientes daños: un edificio multifamiliar en Miraflores, varias paredes en Breña, 90 viviendas en Villa El Salvador, 50 en Barrios Altos, 30 en Barranco. La MIRR no está citada. Sus barrios quedan entonces fuera de la atención pública.

Como ya ha sido señalado, la población de la MIRR fue muy discreta sobre los daños que sufrió, excepto cuando estos eran muy visibles. Esta no ha querido, en su conjunto, arriesgarse a un desalojo por encontrarse de manera ilegal en una zona de riesgo delimitada por Defensa Civil. Discreción por un lado, poco interés por parte de las autoridades por el otro, el resultado ha sido una gestión de crisis cuyas riendas fueron tomadas solamente por los habitantes de los barrios de la MIRR. Si bien los daños materiales fueron a veces importantes, felizmente el sismo no causó víctimas. Algunos habitantes fueron albergados, por lo menos en la noche, por vecinos (fig. 2). Otros dejaron incluso definitivamente su vivienda para irse a vivir donde sus familiares fuera del sector. Frente a la ausencia de apoyo exterior, se implementaron mecanismos de ayuda mutua en el seno de los barrios. Este ha sido el caso de una familia de Villa María del Perpetuo Socorro cuya casa fue destruida. Un local comunal fue puesto a disposición y los habitantes del barrio organizaron una faena (trabajos comunitarios frecuentes en los Andes) para limpiar los escombros. De igual manera, frente a la ausencia de respuesta de las autoridades a su demanda de ayuda para una reubicación, un habitante de las riberas del río Rímac recibió el apoyo de sus vecinos (puesta a disposición de un terreno y de materiales de construcción: esteras y postes de madera), lo que permitió reinstalarse a proximidad de su antigua vivienda destruida durante el sismo. Varias actividades, en particular polladas 9 , fueron organizadas con el fin de recaudar dinero y ayudar a los más afectados. Además, las asociaciones

9 Práctica corriente de los sectores populares que consiste en la venta de un plato preparado a base de pollo con el fin de recaudar dinero. 
territoriales negociaron con los comedores populares comidas gratuitas para las personas más necesitadas durante los 6 meses posteriores al sismo.

Los vacíos de la organización de la gestión de crisis en la MIRR se tienen que asociar a la marginalización y a la exclusión de este espacio urbano, ya observadas en periodo normal. En realidad, la MIRR ha acumulado dos vulnerabilidades: una vulnerabilidad de fondo (marginalización) y una vulnerabilidad de circunstancias que va en el mismo sentido. Al mismo tiempo que fue seriamente dañada por el sismo, la MIRR se inserta en efecto en un espacio (Lima) relativamente poco afectado en relación con las zonas cercanas al epicentro. La gestión pública de la crisis se hizo ahí mínimamente en un contexto de exclusión por parte de los poderes públicos, más movilizados en las provincias más afectadas, y de auto marginalización por parte de los numerosos habitantes deseosos de esconder los daños de sus casas.

\section{INCIDENCIAS}

El sismo de Pisco ha marcado fuertemente las mentalidades y ha dejado hasta ahora huellas profundas particularmente en las zonas más afectadas, en donde la reconstrucción tarda en realizarse, con más de 80 \% de la población damnificada viviendo aún en condiciones provisorias y precarias10. En la MIRR, por el contrario, a menos de dos años después de su ocurrencia y aun cuando los daños son todavía visibles, el sismo parece estar prácticamente olvidado. Algunas casas presentan hasta ahora fisuras y otras siguen estando en vías de restauración. En el caso de la capilla del barrio $1^{\circ}$ de Mayo, cuyo acceso había sido restringido, la fisura que dejaba pasar la luz ha sido solamente tapada por los habitantes con paneles de madera. De manera general, las recomendaciones formuladas por Defensa Civil tras las inspecciones no han tenido eco. Los estudios estructurales de los edificios, así como su rehabilitación, han sido muy parciales por falta de financiamiento. Solamente algunas obras aisladas son observables, y están en su gran mayoría asociadas a proyectos solicitados por las poblaciones locales. En el caso del colegio Guzmán, la reconstrucción de una pared ha sido emprendida en 2008 gracias al apoyo del ministerio de Trabajo a través del proyecto «Construyendo Perú». Sin embargo, los habitantes del barrio tuvieron que aportar la mano de obra y financiar una parte del costo. Así, numerosas construcciones fragilizadas por el sismo, públicas y privadas, no han sido reparadas o lo han sido de manera somera. Estas constituyen, entonces, fuentes de peligro para los próximos sismos, incluso de poca magnitud.

Dentro de este contexto, la población expresa su temor frente a un próximo sismo. Sin embargo, este temor tiende rápidamente a ser minimizado, basándose en los discursos de las autoridades y de la población, que subestiman voluntariamente los daños. Además, es difícil para la población imaginar los efectos de un sismo de mayor magnitud que aquel del 15 de agosto de 2007, por estar solo acostumbrada 
a pequeñas sacudidas sísmicas, frecuentes pero generalmente sin daños. Por último, la costumbre de vivir en un hábitat deteriorado en donde se entremezclan las viviendas dañadas, tanto por el sismo como por otros fenómenos recurrentes ligados a la inestabilidad del suelo, contribuye a reducir el grado de percepción del riesgo de esta población.

Desde el punto de vista de las políticas de gestión del riesgo, las incidencias son también muy débiles en la MIRR. El sismo no ha servido para hacer evolucionar el caso problemático y conflictivo de la ocupación de las riberas del río Rímac. Los barrios que las ocupan están en situación de ilegalidad y son objeto de un proyecto de reubicación por parte de la municipalidad11. Tras el sismo, las modalidades de intervención de los poderes públicos permanecen sin cambios. Como en los años anteriores, no se ha propuesto ninguna medida preventiva y la población simplemente ha sido notificada, una vez más, de la necesidad de dejar libres las zonas de riesgo por razones de seguridad.

Si bien la MIRR suscita poco interés en materia de prevención, el sismo sí ha contribuido a la realización de algunas mejoras puntuales a la escala del distrito del Cercado de Lima. La dirección de Defensa Civil de este distrito ha incrementado temporalmente su personal con el propósito de realizar las inspecciones de daños posteriores al sismo. Para ello, se ha contratado a 25 personas y se ha movilizado tambien a profesionales (ingenieros y arquitectos) de diversas instituciones públicas12. Además, en la perspectiva de futuras crisis, se han formado equipos de brigadistas. Se trata de voluntarios, habitantes de los barrios del Cercado, encargados de apoyar las actividades de Defensa Civil y que pueden ser movilizados en caso de crisis.

Sin embargo estas iniciativas son muy magras frente al reconocimiento, empero acrecentado, del riesgo sísmico en el Perú, y en particular en Lima, por parte de los actores de la gestión de los riesgos y de las crisis, nacionales e internacionales. El tema ha sido objeto de diversas publicaciones recientes (Morales-Soto \& Zavala, 2008; Wyss et al., 2009). Sustentado por los sismólogos del Instituto Geofísico del Perú, este reconocimiento del riesgo potencial en Lima se ha traducido por un reciente diagnóstico del impacto de un sismo de gran magnitud en esta ciudad (Predes, 2009), realizado a solicitud del Indeci y financiado por Cosude (Agencia Suiza para la Cooperación y el Desarrollo). Sin embargo, dado el escaso interés de la Municipalidad de Lima, el riesgo sísmico está aún lejos de estar integrado en las políticas metropolitanas.

11 Ver el artículo de Robert y Sierra en este volumen, pp. 595-621.

12 Este personal procedía sobre todo de los servicios de urbanismo y de transporte de la Municipalidad Metropolitana de Lima (MML). 


\section{Referencias citadas}

BERNAL, I. \& TAVERA, H., 2008 - Estudio de Microzonificación Sísmica en AA.HH. de Lima, 66 pp.; Lima: IGP.

COOPI, 2008 - Estudio de identificación de zonas de peligro y de vulnerabilidad en el Cercado de Lima y El Agustino, Provincia de Lima, 83 pp.; Lima: Proyecto DIPECHO.

D'ERCOLE, R., CHANDES, J., PERFETTINI, H. \& AUDIN, L., 2008 - Le séisme de Pisco du 15 août 2007 : entre urgence et reconstruction. EchoCéo, Sur le vif 2007, http:// echogeo.revues.org/index2109.html

D'ERCOLE, R. \& SIERRA, A., 2008 - Enjeux urbains contradictoires et vulnérabilité accrue dans un espace marginal péricentral : la rive gauche du Rímac à Lima (Pérou). Autrepart, 45: 105-122.

MORALES-SOTO, N. \& ZAVALA, C., 2008 - Terremotos en el litoral central del Perú: ¿Podría ser Lima el escenario de un futuro desastre? Revista Peruana de Medicina Experimental y Salud Publica, 25: 217-224.

PREDES, 2009 - Diseño de escenario sobre el impacto de un sismo de gran magnitud en Lima Metropolitana y Callao, 95 pp.; Lima: Indeci, Cosude.

WYSS, M., TRENDAFILOSKI, G., ROSSET, P. \& WYSS, B., 2009 - Preliminary loss estimates for possible future earthquakes near Lima, Peru, 65 pp.; WAPMERR. 